\title{
Supporting black and minority ethnic students in practice learning
}

\author{
Gill Calvin Thomas ${ }^{1}$, Kate Howe ${ }^{1}$, and Steven Keen ${ }^{2}$
}

Summary: The paper highlights the need of black and minority ethnic (BME) students in England to access support systems to help them overcome the challenges that they face as minority students when undertaking placement learning as part of their social work qualifying programme. It also considers the wider issue of developing supportive anti- oppressive practice with regard to all students undertaking the social work degree; i.e. 'walking the talk' of the values that underpin Social Work practice. Research shows that progression and retention rates for students from marginalised groups is lower than the sector averages and that specific support systems can improve the likelihood of course completion, as well as increasing student confidence.

The paper evaluates a project undertaken to investigate and pilot how a mentoring support scheme and other good practice initiatives can increase the successful completion of practice learning for students from a BME background (and those with English as an additional language).

Key words: black and minority ethnic people; practice learning; social work education

1. Senior Lecturer in Social Work, Centre for Social Work and Social Policy, Bournemouth University

2. Senior Lecturer in Research, Centre for Social Work and Social Policy, Bournemouth University

Address for Correspondence: Centre for Social Work and Social Policy, $4^{\text {th }}$ Floor, Royal London House,, Christchurch Road,, Bournemouth, BH1 3LT. gcalvinthomas@bournemouth.ac.uk

Date of publication: 29th December 2011

37 J. of Practice Teaching \& Learning 10(3), pp.37-54. DOI: 10.1921/ 146066911X623438. @ w\&b 


\section{Introduction}

Imagine a BME (black and minority ethnic) student with English as an additional language who has failed their first Social Work degree placement and been offered an extended period of practice in a different setting in order to give the student a positive chance to complete and evidence competent practice. At an initial meeting with the practice director, the student discloses how miserable s/he had been made to feel and how unkind staff had been. The student's self esteem and confidence is low. Initially looking forward to her first placement, s/he now feels s/ he has been punished. An extended placement is carefully set up - the placement supervisor, who has experience of working with students from marginalised groups, introduces the student into a cohesive and welcoming team. Subsequently, the student successfully completes this extended placement. But it does not always end like this.

BME students have to cope with a complex set of dynamics as they work through a Social Work degree (Aymer \& Bryan 1996). Not only do they have the usual academic demands; but they are also managing structural and psychological factors around their identity as well as direct and indirect experiences of racism. Progression rates in the UK can be improved when universities consider specific strategies to support different groups of students (Hussein 2007, Moriarty et al. 2009). Peer mentoring schemes, as well as recruiting black Social Work educators as role models appear to be of benefit (HEFCE 2002, Rolfe-Flett 2002, Singh 2006, Wilson and Tilse 2006, Simon et al. 2008).

When taking into consideration an American study of college graduation rates (Anon 2007) black student graduation is 10\% below white students in 15 of the 56 colleges surveyed, although in other colleges, black graduation rates are stronger. Possible explanations include, for example, the racial climate being more favourable towards African American students in some colleges more than in others, so that on some campuses, black students feel unwelcome. Rates of graduation appear to have improved where orientation and retention programmes have been set up and where relatively large numbers of black students exist on campus. Mentoring programmes linking 'upperclassmen' with first year students have been successful in improving graduation rates (Anon 2007). Interestingly, the survey also found that colleges based in rural areas had lower graduation rates for black students (Anon 2007).

38 J. of Practice Teaching \& Learning 10(3), pp.37-54. DOI: 10.1921/ 146066911X623438. @ wE-b 
In a study of social work degree students progression in England, Hussein et al. (2009) built on work completed with students beginning their social work programmes between 1995-1998. In their first study (cited in Hussein et al. 2006) personal characteristics such as gender and ethnicity significantly affected progression rates. Following on from this study Hussein et al. (2009) analysed data on all full time undergraduate students enrolling in England between 2003-2005. Part of the analysis was based on GSCC information in relation to practice placements; however the authors note that this information was not adequate to give a significant analysis of the relationship between placement and progression. Clear variations in referral rates within programmes were observed corresponding to region and ethnicity. The South of England had a higher rate of referrals when compared with the North and the Midlands, that is 14\% of students in the South of England compared to $8 \%$ in the North and Midlands. An analysis of ethnicity in the same regions showed that $15 \%$ of BME students were referred compared to $9 \%$ of white students.

These findings and the experience of students' feeling 'punished' as cited in the opening paragraph, led university staff located in a predominantly white, rural community in the South of England (South West Observatory 2007), where the majority of Social Work staff and students are white women, to consider support mechanisms for BME students and their practice learning opportunities. We secured funding from Skills for Care (South West) that enabled the development of a project to pilot support mechanisms and to evaluate their effectiveness - the subject of this paper. Our aim was to adopt a strengths based approach which recognised, sustained and built on the skills and experiences of the students (Mcphail \& Sidvah 2008). This correlates with a Canadian study of social work students in their field placements, in which Barlow \& Hall (2007) propose that having consideration for students' feelings about oppression in their placements can be a foundation to engage students and placement personnel in improving practice and the quality of placements. 


\section{Background}

Throughout the paper the term BME (black and minority ethnic) is used. Whilst 'black' is a limited descriptor e.g. it does not recognise the complexity of the experience of racism, it is accepted by many as highlighting the shared experiences of being discriminated against because of differences in skin colour. The addition of 'minority ethnic' does help to differentiate people's lived experiences; however, we accept the deficiencies in our use of terminology as highlighted in Social Work literature (e.g. see Channer \& Doel 2009).

Indeed, the literature on racism and how Social Work has faced the task of tackling oppression is vast. Ahmad (1994, cited in Keating 2000) acknowledges the contribution that anti-racist Social Work has had in providing an understanding of disadvantage and injustice and believes it to be the forerunner of anti-oppressive practice. Anti-racist Social Work urges all practitioners to develop an awareness of prejudices and biases in interpersonal relationships as well as recognising the power dynamics that produce institutional racism (Dominelli 2002, Singh 2005, Thompson 2006, Graham 2007). Over the years, Social Work has promoted progressive and emancipatory practice i.e. - it is "no longer acceptable to treat everyone in the same way or provide care to individuals based on a set of norms drawn from the majority society' (Graham, 2007, p.4). Issues of social exclusion and discrimination against vulnerable groups in society have been central to a value based approach to Social Work practice and as Graham (2009) recognises, Social Work has adopted a social justice approach as a guide to tackling inequalities.

Social Work education has a history of promoting anti racist practice, arguing for its inclusion in all qualifying programmes. However there is a concern raised by Butler et al. (2003), Graham (2009) and Bhatti-Sinclair (2011) that more recently the focus on anti racism is being diluted within a wider anti oppressive practice perspective. This becomes more problematic when racism becomes invisible in rural areas. Baldwin (1996) highlights there can be a misperception that racism is not an issue, when there is a belief that 'we do not have black people here'. In a predominantly white area, thoughts and beliefs from students and practice educators can often be well-meaning, but imbued with unquestioned racist attitudes. As Bhatti-Sinclair (2011) highlights,

40 J. of Practice Teaching \& Learning 10(3), pp.37-54. DOI: 10.1921/ 146066911X623438. @ wE-b 
it is important to consider how services are delivered (or not) to BME groups in rural settings with a focus on anti racism.

For Social Work educators this focus must also extend to include students from BME backgrounds. The requirement of the Social Work degree to include 200 days of practice learning in an agency setting (DH 2002) places additional demands on students, over and above those of a pure academic degree, and consequently further support mechanisms may be required. Students from a BME background placed in a rural area may be more marginalised than those attending universities in an area with a more diverse population. Anecdotal evidence from our programme had already confirmed that students can become isolated in unfamiliar placements. It is interesting to note that there have been calls to develop well thought-out guidelines to support black students as early as 1989, as students were 'bound to face some form of racism on their placements' (Ferns 1989, p.17; also see Cropper 2000, p.603). Razack's (2001) study into placement experiences of BME students in Canada endorses this assertion, finding that a significant percentage (36\%) encountered oppressive or discriminatory behaviours in placement; 'racial minority students faced additional anxieties ... because of a history of marginalisation and oppression' (p. 228). It can be argued that this experience is exacerbated in isolated communities with little diversity (Givens \& Bennett 2004, Jessop and Williams 2008).

Prompted by implicit evidence about students experiencing racism from staff in social care agencies, members of the university Social Work team invited BME students to informally discuss their perceptions of placements. This resulted in the recognition of a lack of formal support available for these students. Although there is useful guidance on how to prepare students for practice learning and develop standards for agencies offering placements (e.g. Singh 2006) these are aimed at the needs of practice educators, not the needs of BME students undertaking practice learning, nor those who have English as a second language (Rai 2004). Hence, the aim of this project, subsequently funded by Skills for Care (South West) in July 2007 was to investigate, pilot and evaluate specific support structures for BME students on placement, paying particular attention to those who have English as a second language. Therefore, this project sought to offer a safe environment for BME students to express their voices, concerns and experiences (Graham 2009).

41 J. of Practice Teaching \& Learning 10(3), pp.37-54. DOI: 10.1921/ 146066911X623438. @ w\&b 


\section{Methods and profile of respondents}

The project had three discrete elements: each corresponding to project aims of investigating, piloting and evaluating support structures for BME students on placement; focus groups, mentor support and a practice learning conference.

\section{Focus groups}

Focus groups are described as a loosely constructed discussion with group of individuals brought together for the key purpose of the study; the researcher usually acts as a guide (Sarantakos 2005). The two group discussions were semi-structured in format i.e. the project leader had a set of open questions to direct discussion.

The first focus group was made up of students who responded to an invitation to be part of the project and who identified themselves as being from a BME background. This group met twice: once at the beginning of the project to discuss students' placement experiences and once towards the end of the project to explore factors affecting a successful placement. Six students participated; three second year students and three third year students. Of the six students, four spoke English as an additional language - all were female, their ages ranging between 25 and 40 years.

Three qualified practice educators and one placement supervisor were recruited to form a second focus group to discuss their experiences of working with students from marginalised groups and to identify good practice. This experienced group of practitioners have worked with a variety of Social Work programmes and are all currently engaged in practice education. Again, all were female; three were white British and one was from a BME background. This group met once at the beginning of the project and once towards the end of the project. Both project leaders (GCT/KH) are white British and are qualified practice teachers. Each focus group was facilitated by one of the project leaders; the other project leader acting as note-taker.

The student focus groups were informal and based on a flexible interview format in which the facilitator was able to keep the group focused but also allowed spontaneous participation in order to

42 J. of Practice Teaching \& Learning 10(3), pp.37-54. DOI: 10.1921/ 146066911X623438. @ wE-b 
encourage students to explore their experiences. The students had joined the focus group voluntarily, their agreed goal to make a positive contribution for future students. The project leaders enabled the students to feel safe by agreeing ground rules during the first session and ensuring confidentiality. The students agreed that their comments could be used in disseminating the learning from the project as long as they agreed the statements and no identifying data would be used. The data gathered for each focus group was analysed thematically according to usual qualitative research practice (Miles \& Huberman 1994). The recommendations and reporting of actual statements were agreed with the group following the final informal focus group. The practice educator/placement supervisor group followed a similar methodological and analytical pattern.

\section{Mentor support}

There are many definitions of mentoring (e.g. Wilson \& Tilse 2006; McDowall-Long 2004; Cropper 2000). For the purposes of this project it was decided to use the following: '...mentoring is typically described as a one to one relationship between a more 'experienced' or 'expert' mentor facilitating or supporting the learning in another' (Wilson \& $\&$ Tilse 2006, p. 179). The project leaders wished to offer students confidential and independent support for the duration of their placement (100 days) to ascertain whether this type of mentoring relationship might build a student's confidence, ability to learn and hence capability to meet the required practice learning competences.

As Cropper (2000) points out, for any mentoring to be successful it had to be framed within an anti oppressive model. Mentoring can be seen as an individual solution to a structural issue and we wanted to ensure that any subsequent support was from an empowering and strength based perspective. The mentor needed to be able to understand and support the students' personal experience as well as having insight into the broader political and societal context of their experiences. After a careful recruitment process the project contracted with a black female social worker employed in the local area who had insight and a critical understanding of discrimination as well as experience of working with adult learners. Her brief, as a consultant, was to assist BME students to identify issues that helped and hindered their learning experiences

43 J. of Practice Teaching \& Learning 10(3), pp.37-54. DOI: 10.1921/ 146066911X623438. @ wEb 
as well as meet their support needs. She also attended the focus group meetings. Although there was complete confidentiality about the nature of the support offered to the individual student, there was agreement that she could report her overall findings of the issues that emerged from her contact with students. This also led to her making her own recommendations for future practice that have been incorporated into this manuscript. She also had the role of 'critical friend' to the project leaders and was able to offer constructive advice about the direction of the project and feedback on the thematic analysis of findings.

\section{Practice learning conference}

The final discrete element of project methods was a practice learning conference, held to evaluate and disseminate focus group findings and to formulate guidelines for good practice. The conference was organised by the local Learning Resource Network who hold a database of all practitioners involved in practice learning in the area. Invitations were extended to practice educators, placement supervisors, training officers from three local authorities and university tutors. The conference attracted a good cross section of 50 individuals from the practice learning community. Approximately one quarter of the practice educator/placement supervisor group was male. All of the training officers and university tutors were female. The majority of attendees were white British, reflecting the local, predominantly rural, community.

Findings from the focus groups and mentor support were disseminated by the project leaders and were a key element of the conference. Groups of participants were formed during the conference to debate these findings. The two project leaders (GCT/KH), with members of the practice educator/placement supervisor focus group, facilitated the groups aiming to elicit as many points of view as possible. Group members were given 'post it notes' to allow spontaneity and freedom of expression. Following the conference the project leaders reflected on the content of 'post-it notes' and other conference discussion for the purpose of forming recommendations. Those themes reinforced findings from the focus groups and led to the agreement of a set of good practice guidelines as detailed towards the end of the next section of this paper.

44 J. of Practice Teaching \& Learning 10(3), pp.37-54. DOI: 10.1921/ 146066911X623438. @ wËb 


\section{Project evaluation and discussion}

This section is again split into three discrete but related elements, reflecting the process of the project: focus groups, mentor support and the practice learning conference. Verbatim quotes have been italicised.

\section{Focus groups}

Student focus groups

The student focus groups offered powerful evidence that in some practice placements there has been a failure to acknowledge and value diversity. In a minority of cases, this led to overt racism where agency practitioners did not see beyond the colour of their skin e.g. 'In my previous placement I was 'that black woman'; it went as far as my skin and no further' (Student A). Assumptions had been made about students' ethnicity, with many instances of stereotyping and little understanding of different cultures. Another student had been asked to talk with a service user 'because they were from the same culture' (Student B) yet in fact they were from very culturally different parts of Africa.

Interestingly, some students felt more accepted by service users than their colleagues. Others did experience racism from service users and needed support from practice educators and the placement team.

Some students report a sense of being 'watched', and that they are expected to be an expert in diversity issues... 'They keep quiet and expect me to say something and I don't because I think it may offend' (Student C). In other placements a 'colour blind' approach has been adopted so that a student's identity is not acknowledged; leading to a sense of isolation, lack of confidence and a questioning of staff values.

Students talking about 'keeping their heads down' (Student B) concurs with findings from Barlow \& Hall's study of Social Work field education in Canada (2007) where they found students had often internalised discrimination and racism, resulting in externalised coping strategies in order to get through their placements. This is not always positive. Issues of power, control and fear of poor performance can be barriers to learning and to seeking support. Although practice educators might think the placement is going well the students may be denying their own values simply to complete the placement. Indeed students who are

45 J. of Practice Teaching \& Learning 10(3), pp.37-54. DOI: 10.1921/ 146066911X623438. @ w\&b 
concerned they may be failing their placement can feel even less able to ask for support.

BME students using English as an additional language discussed how dissimilar professional Social Work language is to everyday spoken English. Students feared showing any weakness in their grasp of English and professional Social Work language, because of the assessment role of the practice educator. Staff or practice educators who were less sensitive to student needs made remarks that students felt 'put them down' reinforcing the fears they already held. One practice educator had said to a student, 'I am not an English teacher', in response to a request for help with report writing. Direct work with service users was found to be less stressful and more rewarding because they were using every day language, and avoided jargon. Formal observations were seen as causing high levels of anxiety resulting in students having more difficulty using the right words.

Students with more positive experiences have reported having supportive practice educators and placement supervisors. Where practice educators were proactive in talking about diversity, students felt more able to discuss their learning needs 'in a comfortable way' (Student B). When teams welcomed difference and saw diversity as positive, BME students felt valued and accepted. It was then that knowledge and experience was shared on an equal basis. This reinforces the argument from research carried out by Channer and Doel (2009) with post-qualifying students from a BME background, where they found that respecting different needs was more likely to make an educational experience more meaningful.

The students in this study believed strongly that placement teams needed to be well prepared before a student's arrival. Their experience led them to believe that confident, knowledgeable and skilful managers set a good example and promoted a safe environment for student learning. Students too thought that they needed to spend time before the beginning of a placement getting organised and ready to undertake the placement. This included having a supportive, open and honest relationship with their personal tutor at the university. Students reflected how this relationship then enabled them to begin to develop professional relationships and gave them ongoing support from outside of the placement.

46 J. of Practice Teaching \& Learning 10(3), pp.37-54. DOI: 10.1921/ 146066911X623438. @ wËb 
Supporting black and minority ethnic students in practice learning

Practice educator/placement supervisor focus group

Practitioners were able to reflect on the analysed findings of the first student focus group and also comment on their experiences of working with BME students. Some had worked with students who had experienced hostility in previous placements and recognised that support was needed. This has resonance with Rowe (1990) who describes hostility and micro-inequalities as an environment in which small but harmful features can have an effect on people joining a group which they do not feel part of. This could be equated to a 'dripping tap' effect where students are subjected to different treatment, for example, irritation in the tone of voice being used, being ignored within the team, or not greeted as other members of staff are. Rowe (1990) suggests these are not actionable violations but are a subtle indication of lack of respect because the person is not part of the 'in' group. On the basis of these and other student experiences the practice educator/placement supervisor group put forward specific recommendations to ensure good practice.

In doing so, these practitioners acknowledged the appalling experiences of some BME students and concluded that practice placements for BME students should be carefully chosen, particularly for students with English as an additional language. Ideally placements should be tried and tested, with staff and teams experienced in working with BME students and universities, and who showed cohesiveness, commitment and demonstrable awareness of diversity issues.

The group also discussed the difficulties that BME students may face in this predominantly white geographical community. Bird (1996, cited in Cropper 2000, p. 603) offers a telling quote from his research: 'when I have done placements I am very conscious of the fact that I am Asian: it's fine on the course, but when you go out on placement you sense it ... I am aware of racism in the profession'. The group argued that placement staff should therefore plan to give a student from a BME background more time, particularly at the beginning of the placement to be able to settle in and feel accepted by the agency. Moreover, staff should be empathic and ensure that they distinguish the student as a unique individual and celebrate their diversity. It was suggested that in so doing, students who have had poor experiences, could be helped to develop their confidence and self-esteem in placement. Staff who listened to students and accepted them as members of the team could enable students to feel understood in their own right.

47 J. of Practice Teaching \& Learning 10(3), pp.37-54. DOI: 10.1921/ 146066911X623438. @ w\&b 
The group agreed that students with English as an additional language would often face multi layered difficulties whilst on placement and need support from university and placement to not only acquire confidence in their written and spoken English, but also in acquiring the professional language and jargon of specific agencies. However, they were resolute in believing that there should be no compromise in the standard of work, which could result in putting service users at risk. Rai (2004) agrees and comments that whilst there can be a 'diversity on Englishes' (2004, p. 831) this needs to be balanced against the importance of maintaining Social Work professional standards. It may therefore require a practice educator with the knowledge, skill and willingness to give more time and support when working with a student with English as an additional language to enable verbal and written critical analysis and reflection on their practice.

\section{Mentor support}

The consultant mentor offered 1:1 support to 5 BME students, through face to face meetings and telephone contact. Students valued the consultant's role, commenting that it was important to have an independent and knowledgeable person outside of the assessment process, who could also challenge them. The consultant 'was important in the sense that she was someone who could listen to my concerns on a one to one basis giving encouragement where needed' (Student D). The group sessions were also classed as interesting as 'she made us consider challenging situations and how we could best deal with them instead of always accepting them for fear of rocking the boat' (Student E). The mentor became a critical friend, and because she was outside of the assessment process the power in the relationship was able to be shared more equitably. Embedding the support within the practice learning opportunity instead of as a reaction to problems in placement is therefore an empowering approach, one that enables students to build on their strengths and resilience.

The positive effect of mentoring is also recognised when the impact of an increasingly diverse student population on progression and retention on Social Work programmes is considered (Moriarty et al.. 2009). Hussein's research (2007) has found that people from minority ethnic groups, as well as men and students with disabilities have lower

48 J. of Practice Teaching \& Learning 10(3), pp.37-54. DOI: 10.1921/ 146066911X623438. @ wE-b 
progression rates than other students on Social Work programmes. Variations in progression of social work students in England (Hussein et al. 2009) indicate that the lowest percentages of students passing at first attempt (40\%) are black students or those with 'other' ethnicity. In terms of failing a programme, the highest percentage is among Asian students (5\%) followed by men and those from black or 'other' backgrounds (3\%). Earlier studies evidence that progression is improved when universities consider specific strategies to support different groups of students. Peer mentoring schemes as well as recruitment of black Social Work educators as role models have been identified as beneficial (HEFCE 2002, Rolfe-Flett 2002, Singh 2006, Wilson \& Tilse 2006, Simon et al. 2008).

Yet, the issue of whether BME students need to be supported by mentors from a BME background has been the subject of some debate. The consultant, when evaluating the service she had provided, suggested that it is more important to receive mentoring from an individual who acknowledges, understands and is able to identify interconnecting themes of analysis such as difference and identity, power, reflexivity and personal and political' (Cropper 2000 p.602) and able to reflect, rather than emphasise the race or ethnicity of the mentor. This accords with Simon et al.'s (2008) conclusions in citing Thomas's (1998) model of cross-race mentoring where the relationship can be successful if each participant in the dyad has complementary styles in how they engage with ethnicity and race-related issues. This will inform and guide the staff team when recruiting a future team of mentors.

\section{Practice learning conference}

The conference was well attended by a wide audience of university tutors, practice educators, placement supervisors and/or training officers. Findings from focus groups and the mentor support aspects of the project were presented to, discussed and evaluated by conference participants. The work undertaken in the focus groups and the conference led to the development and agreement of a set of good practice guidelines.

49 J. of Practice Teaching \& Learning 10(3), pp.37-54. DOI: 10.1921/ 146066911X623438. @ w\&b 


\section{Good practice guidelines}

Teams and learning environments can change from year to year, therefore, the quality assurance of placements should be ongoing as should support offered to develop placements where issues have been identified. When a placement has been identified for a student from a BME background, discussion should be carried out in the university team before the student begins to reflect on how racism could affect the student in the agency. In addition strategies should be developed and decisions reached as to how racism could be addressed. Alongside this a strategy should also be developed to identify how outcomes could be evaluated as well as identifying how effective the strategy had been in supporting the student within the learning environment.

Feedback from students tells us that where members of a team feel part of the student learning experience, student feels valued and supported. Consequently, it should follow that placements should be well prepared and offer a good quality supportive learning environment in which staff are engaged in learning and are interested in developing their own practice. Practice educators and placement supervisors should be offered regular training and updates in line with GSCC requirements for continuing professional development.

All students should be encouraged by the HEI to contact their practice educators before the placement begins, including those practice educators who are 'off site'. Practice educators who begin to build a relationship with the student and who acknowledge cultural and ethnic difference and address any issues that might arise in the placement, empower BME students to work in partnership with them from the beginning.

Students feel more supported when placement supervisors and practice educators are comfortable with diversity and acknowledge strengths. This is particularly important in preparing for the practice learning agreement where students from a BME background may be empowered by having a section where they can discuss their identity and individual learning needs. Using strengths based approaches to discussing culture, ethnicity or having English as an additional language (EAL) ensures that any learning or cultural needs are considered and acknowledged. Strategies for support can then be recorded and agreed.

The role of the practice educator is particularly important in

50 J. of Practice Teaching \& Learning 10(3), pp.37-54. DOI: 10.1921/ 146066911X623438. @ wE-b 
helping students understand complex systems of assessment during placement. In addition, the professional language used in social work can be challenging, particularly to a student who has EAL. Therefore the practice educator/placement supervisor is paramount in enabling students to become familiar and confident with that language. Students with EAL find practice educators who help with the first draft of their written work particularly helpful in developing their own use of professional language. In addition it is helpful to recognise that students who have English as an additional language may find it difficult to maintain their usual standard of English when anxious or when being assessed. Giving students the opportunity to have an independent mentor outside of the assessment process may help build on strengths and enable students to deal with issues appropriately.

\section{Conclusions}

The project has highlighted the need for social work educators to be constantly mindful of the need to adopt pro active anti racist strategies. The authors recognise the criticism made by Graham (2009) that anti racism can become marginalised within the wider field of anti oppressive practice and can result in taking your eye off the proverbial ball. It is clear that Social Work students from a BME background continue to experience racism during their university career experience and strategies should be in place to support their learning in placement. However, this needs to be in the context of challenging the social structures that maintain these attitudes and behaviours, so there also must be robust anti racist standards in place, alongside a programme of education to develop the understanding and skills of the placement staff.

We agree with Butler et al. (2003) who recognise that the placement site and university need to be constantly and consciously aware of developing anti-racist practice. In the course of acknowledging that white people cannot truly understand the lived experiences of racism (within this specific English context) (Bhatti-Sinclair 2011), the project raised awareness of how a team approach and commitment to good practice within placement can enable students, particularly those from a BME background, to have a positive learning experience.

The production of good practice guidelines when working with BME

51 J. of Practice Teaching \& Learning 10(3), pp.37-54. DOI: 10.1921/ 146066911X623438. ๑ wEb 
students adds to the body of evidence which encourages all professionals involved in placement learning to reflect on their practice. In many ways the guidelines can be seen as no more than the good practice all students should expect from high quality placement support. However, it is even more important that students from marginalised groups benefit from an approach to learning that values their strengths and skills.

Following on from this project, the authors have implemented the guidelines which have resulted in a number of changes in placement matching and support. This has strengthened the support offered to the students and importantly made the expectations of the placement and practice educators even more transparent. There is now an open dialogue between students and the immediate social work lecturing team and the wider practice learning educators about all aspects of anti oppressive practice. Accordingly our students are now even more supported and equipped to report on and challenge oppressive or discriminatory behaviours.

\section{References}

Anon (2007) Black student college graduation rates inch higher but a large racial gap persists. Journal of Blacks in Higher Education, Winter 2007. Available at: www.jbhe.com/preview/winter07preview; html [accessed $13^{\text {th }}$ October 2011].

Aymer, C. and Bryan, A., (1996). Black students; experience on social work courses: accentuating the positives. British Journal of Social Work, 26, 1-16

Barlow, C. and Hall, B. (2007) What about Feelings? A Study of Emotion and Tension in Social Work Field Education. Social Work Education, 26, 4, 399-413

Baldwin, M., 1996. White racism: Is it really 'No Go' in rural areas? Social Work Education, 15, 1, 18-33

Bhatti-Sinclair, K. (2011) Anti-Racist Practice in Social Work. Basingstoke: Palgrave Macmillan,

Butler, A. Elliott, T. and Stopard, N., 2003. Living up to the standards we set: A critical account of the development of the anti racist standards. Social work Education, 22, 3, 271-281

Channer, Y. and Doel, M. (2009) Beyond qualification: Experiences

52 J. of Practice Teaching \& Learning 10(3), pp.37-54. DOI: 10.1921/ 146066911X623438. @ wE-b 
of Black social workers on a post- qualifying course. Social Work Education, 28, 4, 396-492

Collins, S. Gutridge, P. James, A. Lynn, E. and Williams, C. (2000. Racism and anti racism in placement reports. Social Work Education, $19,1,29-43$

Cropper, A. (2000) Mentoring as an inclusive device for the excluded: black students' experience of a mentoring scheme. Social Work Education, 19, 6, 597-607

Dominelli, L. (2002) Anti-oppressive Social Work Theory and Practice. Palgrave Macmillan. Basingstoke

Department of Health (2002) The Requirements for Social Work Training. London: TSO.

Ferns, P. (1989) Getting the most out of placements. Community Care. 31/8/89, 17-19

Given, N. and Bennett, S. (2004) Tentative Progress in a mainly white setting: hearing from trainee teachers from ethnic minority backgrounds. Race Equality Teaching, 23, 1, 39-44

Graham, M. (2007) Black Issues in Social Work and Social Care. Bristol : Policy Press/University of Bristol

Graham, M. (2009) Reframing black perspectives in social work: New directions? Social Work Education, 28, 3, April 2009, . 268-280

HEFCE (2002) Successful Student Diversity Case studies of practice in learning and teaching and widening participation. Edited by Janet Powney

Hussein, S., Moriarty, J. Manthorpe, J., and Huxley, P. (2006) Diversity and Progression in Social Work Education in England: A report on progression rates among DipSW students, London: GSCC

Hussein, S. Moriarty, J. Manthorpe, J. and Huxley, P. (2007) Diversity and progression amongst students starting qualifying programmes in England between 1995 and 1998; A quantitative study. British Journal of Social Wor, $k$ 38, 8, 1588-1609.

Hussein, S. Moriarty, J. and Manthorpe, J. (2009) Variations in Progression of Social Work Students in England: Using student data to help promote achievement: Undergraduate full-time students' progression on the social work degree. Social Care Workforce Research Unit, King's College. London: GSCC

Keating, F. (2000) Anti racist perspectives: What are the gains for social work. Social Work Education, 19, 1, 77-87

McDowall-Long, K. (2004) Mentoring relationships: Implications for practitioners and suggestions for future research. Human resource Development International, 7, 4, 519-534

53 J. of Practice Teaching \& Learning 10(3), pp.37-54. DOI: 10.1921/ 146066911X623438. @ w\&b 
Miles M.B. and Huberman M.A. (1994). Qualitative Data Analysis: An expanded sourcebook. $2^{\text {nd }} \mathrm{ed}$. Thousand Oaks, CA: Sage.

Moriarty, J., Manthorpe, J., Bharat, C., Jones, G., Wenham, H., and Hussein, S. (2009) Hanging on a little thin line; Barriers to Progression and Retention in Social Work Education, Social Work Education, 28, 4, 363 -379

Rai, L. (2004) Exploring literacy in social work education: A social practices approach to student writing, Social Work Education, 23, 4, 149-162

Razack, N. (2001) Diversity and difference in the field education encounter; racial minority students in the practicum. Social Work Education, 20, 2, 219-231

Rolfe-Flett, A. (2002) Mentoring in Australia; A practical guide. Frenchs Forest. NSW: Prentice Hall [cited in Wilson S and Tilse, C. 2006 Mentoring the statutory child protection manager: A strategy for promoting proactive, outcome focused management. Social Work Education, 25, 2, 177-188.

Rowe, M. (1990) Barriers to equality: The power of subtle discrimination to maintain unequal opportunity. Employers Responsibilities and Rights Journal, 3, 2, 153-163

Simon, C., Roff, L. and Perry, A. (2008) Psychosocial and career mentoring: Female african american social work education administrators' experiences. Journal of Social Work Education, 44, 1, 9-22

Sarantakos, S. (2005. Social Research. $3^{\text {rd }}$ ed. Melbourne: Macmillan Education Australia.

Singh, G. (2005) Guidance for Individuals and Organisations: Developing an anti racist mind set. Available at: www.lrcn/diversity.net. [Accessed $8^{\text {th }}$ July 2007]

Singh, G. (2006) Developing and Supporting black and ethnic minority practice teachers and assessors. Leeds: Skills for Care/Practice Learning Taskforce

South West Observatory (2007) Population Structure in the South West. Available at: http://www.swo.org.uk/sosw2007/web/section_11.html. [Accessed July 7th 2007]

Thompson, N. (2006) Anti Discriminatory Practice. $4^{\text {th }}$ edition. Basingstoke: Palgrave Macmmillan

Wilson, S and Tilse, C. (2006) Mentoring the statutory child protection manager: A strategy for promoting proactive, outcome focused management. Social Work Education, 25, 2, 177-188

54 J. of Practice Teaching \& Learning 10(3), pp.37-54. DOI: 10.1921/ 146066911X623438. @ w\&-b 